\title{
Multilingualism in Young Children: Parents' and Teachers' Views on Effectiveness of Communication and School Performance
}

\author{
Selina L. P. Mushi \\ Teacher Education Department \\ Northeastern Illinois University \\ USA
}

\begin{abstract}
The research conducted focuses on children's use of multiple languages in their natural environments at home and at school. The study examined factors that triggered use of, and fluency in multiple languages, and how fluency in different languages related to thought processes, communication, and school performance. Parents' and Teachers' views were the main sources of information. Data were collected in 3 schools from Kilimanjaro, and Arusha in Tanzania. The 3 schools were determined to include multilingual children; with all languages (two or more) being used on a regular basis. The data included parent questionnaire responses, parent interview notes, and teacher observation notes and tallies/frequency counts of multilingual children's instances of clear communication using multiple languages. during class interactions. Multilingual children's school performance was determined from existing test scores in four selected school subjects, English, Kiswahili, Math and Science. These subjects were considered to be key subjects in the school curriculum. The study results revealed school-related, and family-related factors that triggered and supported childhood multilingualism, parents' and teachers views on multilingualism and its role in children's thought processes, communication, and school performance in the key subjects.
\end{abstract}

Keywords: Multilingualism, Communication, Interlanguaging, Translanguaging, Parental Support, Curriculum Content, Performance

\section{Introduction}

Neuroscience has demonstrated that language development is rooted in the cognitive maturation process. By the 29th week of gestation [1] predispositions for language acquisition are already present, and they affect all aspects of mental development [2]. A certain level of cognitive development has to be reached before the first word is uttered [3], [4], [5]. To express thought, a child draws from the language faculty in the brain and projects the intended or experienced thought onto someone else's attention by use of verbal production, physical reaction or gesture. In typically developing children, verbal language is the primary mode of communication, which is also an indication of cognitive functioning. The rapid development of language in the early years [6]; [1]; raises important questions about mastering two or more language systems at the same time in childhood. The centrality of verbal language use as a medium for communication and for learning school curricula calls for clearer understanding about how young children develop, use and manage two or more languages as they process and express themselves in their daily functioning as well as in formal school learning.

Classroom teachers may wonder if multilingual children use up a large portion of their brain for only language, leaving little room for other cognitive abilities. Research on school performance has tended to show bilingual and multilingual children performing at lower rates compared to English monolingual children [7], [8] even though some studies have found no difference [9]; and other studies have even found some advantages for learning in multiple languages [10]. Parents in some developing countries tend to push their children to learn English, and they pay large sums of money for this purpose [11]. Such parents believe that mastering English at an early age is the only path to academic success. Obviously, a multilingual child speaks and understands multiple languages, a definition that has not always been used in research on multilingual children's school performance. This study focused on children who were fluent in two or more languages

\section{Conceptual Framework}

The study is contextualized in three main tenets or conceptualizations of early language learning. First, neuroscience has shown that young children need exposure to stimulating environments to help wire their brains [12]; [13]. It happens that the first three years of development are critically important for both brain 
growth and language acquisition. Secondly, most children are capable of learning two or more languages with no cognitive delays [14]. Thirdly, truly multilingual children acquire the multiple languages naturally within their environments, and use the languages for fulfilling their day-to-day needs, including school learning. Based on Piaget's constructivism approach to learning and Vygotsky's social-cultural perspective on learning, children need and use both their immediate environment (spontaneous play) and parental support (scaffolding) to learn the languages that they need to function effectively within their contexts.

It seems that on the one hand, children's brains are pre-wired to learn any number of languages they get exposure to and which they have use for, but on the other hand, naturally multilingual children face stiff barriers in communicating using the languages they have already acquired, especially in school settings. In some cases, children have lost their native languages when they realized that there was a more important language that was "for success" in school and later in life, and this attitude was, unfortunately, also supported by parents and teachers. It is within this context that this study sought to find out parents' and teachers' perspectives on children's multiple languages as the languages relate to the children's ability to communicate their thoughts, while the multiple languages might even compete with the medium of instruction in learning the prescribed school curriculum.

\section{Related Literature}

The role of parents in their children's learning of language cannot be overemphasized [15]. Parental support is at the center of successful acquisition of the language sounds and use of those sounds to make meaning, to finally be able to transfer the meaning using words understandable to a listener who will make sense of what the child is saying. Parental support helps make the task of learning a language more manageable by providing good models of pronunciation, word meanings, and connecting utterances to actions within context. Research has shown that parents have strong influence on not only their children's learning of multiple languages, but also on the changes of the linguistic ecology as a whole [16].

Parents have also been seen as equal partners and decision makers alongside teachers in their children's learning of multiple languages [17]. School-centered parental involvement has been characterized to have inferior learning outcomes for children, in favor of more collaborative partnerships. It can be argued by extension that collaborative partnerships between teachers and parents are even more important in serving multilingual children, who come to school with multiple languages, only to find out only one language is needed, and most probably a new language.

While the adaptive nature of the brain has been credited for learning of multiple languages [1], [13], [18] such learning is not without struggle. Semilingualism [2], [8], challenges in school learning [9], comparison to language impairment [7], and poor performance has been linked to using languages other than the designated language of instruction. However, the emerging trend in the literature focusing on use of multiple languages in learning at school promises a more informed path to understanding the role of early multilingualism in learning in general, and in mastering specific types of content within the school curriculum.

Researchers and educators need to embrace neuroscience and re-focus attention on the early years as a unique window for learning multiple languages [1], [6], [13, [18], [19], which presents an advantage to young children's linguistic development. Parents and teachers need to collaborate towards achieving the same goals for young children in multilingual contexts in order to excel on the gift of acquiring several languages. Such re-focusing has to start with parents' and teachers' own understanding, perspectives, attitudes and willingness to see value in children's early multilingualism.

Rather than focusing only on the outcome of schooling, e.g., passing national exams, or being able to communicate in English, parents and teachers can value children's overall learning in their everyday lives, and preparation for engaging meaningfully in socially, culturally, and economically productive and dignifying activities as adults. With the limited window of natural acquisition, multiple languages are an asset that need to be embraces, valued, nurtured and built upon.

\section{Approach and Methods}

Sampling of study participants was targeted at children who already spoke two or more languages fluently. Children aged 5-12 years in 10 classrooms in 3 schools were studied. A total of 107 multilingual children were studied among a larger group of 668 children. Questionnaire data provided background information on the children, interaction with their families and communities, and general use of multiple languages. Parent interviews helped highlight activities and interactions that related closely to learning English, Kiswahili Math and Science outside school. In addition to examining triggers of multiple languages at an early age, the study sought to find out how fluency in multiple languages related to children's performance in the school curriculum, and if there were any advantages or disadvantages of using multiple languages in learning school subjects. 
The four school subjects were selected on the basis of their emphasis in the school curriculum, from both parents and teachers. Examination of composite scores on previous tests on these selected subjects provided an already documented record of the children's performance in these key subjects taken together. Some performance records were available in actual scores, and in some cases in individual subjects (English, Kiswahili Math and Science) separately. For uniformity and comparison purposes, the quantitative scores were converted into rankings, so that all scores could be in one form as composite ranking scores on all four subjects.

\section{Study Results}

The study findings revealed factors that triggered and supported use of multiple languages in children; relationship between fluency in multiple languages and how children used their thinking skills and communication; and the relationship between multiple languages and performance in selected school subjects. The results also revealed disadvantages faced by multilingual children when they were forced to use only one of the languages they spoke.

\subsection{Factors That Triggered and Supported Use of Multiple Languages}

The factors that triggered and supported ability to use multiple languages fluently included having multilingual parents, engaging in play activities with multilingual peers, interacting with grandparents and participating in cultural activities. Other factors were reading materials written in different languages, writing games and songs in Kiswahili and English, and the dual emphasis on both languages within the school curriculum. Having a role model who used multiple languages, and friends who spoke the different languages were other supportive factors, especially when the languages were used with a sense of pride by the role models.

\subsection{Multilingual Children's Thought Processes}

Sixty-seven percent of parent questionnaire responses indicated that using multiple languages at home and in the community broadened their children's world outlook and enhanced classroom learning. Teacher interviews based on two-week classroom observations of multilingual children revealed that the children demonstrated clarity in expressing ideas in Kiswahili ( $96 \%$ of the time) and in native languages ( $73 \%$ of the time). Teachers categorized children's responses as "clear" or "not clear" as children expressed their thoughts in class using multiple languages. Results showed that children were better understood when they used Kiswahili compared to when they used English or mother tongue. It was obvious that children used all the languages they knew. "The children use all their languages to try to be precise in the meaning they are putting across", remarked one teacher. Another teacher said: "When forced to communicate in only one language, especially English, children tend to use words that interfere with the intended meaning, because focus tends to be on the language, and not on the message".

Code-switching was perceived as a way to capture meaning in self expression. The multilingual children used words from mother tongue, Kiswahili and English in the same sentence. Such code-switching was used mostly in play activities, but also in formal classroom learning interactions with the teacher. The following were also confirmed by parents and teachers: (i), Use of multiple languages enabled children to think clearly and communicate with precision, (ii) Children experienced a sense of flexibility in the choice of language to use when discussing classroom content, i.e., freed up children's thought processes, and (iii) Unrestricted use of multiple languages allowed for creativity and encouraged inquisitive minds. For example, one teacher reported that children argued about why "nkaambariko", a word with negative connotation in Meru cultures was used to shame girls who did not marry as early as expected, but the same word did not apply to boys in similar situations. This "debate-like discussion" took place in three languages, Kimeru, Kiswahili and English, in a fourth grade, without the teacher's guidance. Children were mixing the three languages as the need arose, in order to accurately represent and communicate their thoughts and inquisitiveness on the concept.

\subsection{School Performance of Multilingual Children}

Test score rankings used as secondary data to estimate multilingual children's performance within their groups. Each multilingual child's performance was estimated within a group that included monolingual children. Classroom teachers were requested to identify multilingual children on the score sheets of previous tests and exams in English, Kiswahili, Math and Science as composite scores. The scores and rankings of the multilingual children were identified in relation to whole class performances. The performance ranking of each multilingual child's score was highlighted. Tables 1-3 summarize the performance of multilingual children in English, Kiswahili, Math and Science as composite scores. The scores provided were from three Schools. Five classrooms were observed in School 1 as shown in Table 1. 
Table 1. Performance of Multilingual Children in School 1

\begin{tabular}{|l|l|l|l|l|l|}
\hline Grade/Group & $1 \mathrm{~A}$ & $1 \mathrm{~B}$ & 2 & 3 & 4 \\
\hline Class Size & 46 & 40 & 35 & 62 & 91 \\
\hline $\begin{array}{l}\text { Number of } \\
\text { Multilingual } \\
\text { Children }\end{array}$ & 4 & 3 & 3 & 3 & 5 \\
\hline $\begin{array}{l}\text { Multilingual } \\
\text { Children's } \\
\text { Performance } \\
\text { in Ranking }\end{array}$ & $\begin{array}{l}\text { From } \\
\text { 2nd to }\end{array}$ & $\begin{array}{l}\text { From } \\
\text { 2nd to } \\
7 \text { th }\end{array}$ & $\begin{array}{l}\text { From } \\
\text { 3rd to } \\
21 \text { st }\end{array}$ & $\begin{array}{l}\text { From } \\
\text { 3rd to } \\
18 \text { th }\end{array}$ & $\begin{array}{l}\text { From } \\
\text { 2nd } \\
\text { to } \\
\text { 24th }\end{array}$ \\
\hline $\begin{array}{l}\text { Multilingual } \\
\text { Children's } \\
\begin{array}{l}\text { Performance } \\
\text { (\% within } \\
\text { Group) }\end{array}\end{array}$ & $\begin{array}{l}\text { Upper } \\
13 \%\end{array}$ & $\begin{array}{l}\text { Upper } \\
17.5 \%\end{array}$ & $\begin{array}{l}\text { Upper } \\
60 \%\end{array}$ & $\begin{array}{l}\text { Upper } \\
29 \%\end{array}$ & $\begin{array}{l}\text { Upper } \\
26 \%\end{array}$ \\
\hline
\end{tabular}

School 1 had a total of 18 multilingual children within the five groups/classrooms. Seventeen of the 18 multilingual children observed in School 1 (6.2\% of all 274 children from School 1) performed within the upper $29 \%$ of their respective classes/groups as seen in Table 1. The 4 multilingual children in Group 1A performed within the upper $13 \%$ of the group of 46 children. The 3 multilingual children in Group 1B performed within the upper $17.5 \%$ of the 40 children. In Group 2, 1 of the 3 multilingual children ranked $21^{\text {st }}$, thus performing within the upper $60 \%$ of the group of 35 children. The 3 multilingual children in Group 3 performed within the upper $29 \%$ of the group of 62 children; and the 5 multilingual children in Group 4 performed in the upper $26 \%$ of the group of 91 children. Overall in School 1, all but one multilingual children performed better than $71 \%$ of their respective groups. This means that all the multilingual children were in the top segment of the group in terms of performance.

Two groups were observed in School 2. The two groups were large class sizes of 89 and 75 children respectively. Table 2 shows a summary of the findings from school 2 as was observed from composite ranking scores in the four selected key subjects, English, Kiswahili, Math and Science.

Table 2. Multilingual Children's Performance in School 2

\begin{tabular}{|l|l|l|}
\hline Grade/ Group & 2 & 3 \\
\hline Class Size & 89 & 75 \\
\hline $\begin{array}{l}\text { Number of Multilingual } \\
\text { Children }\end{array}$ & 15 & 22 \\
\hline $\begin{array}{l}\text { Multilingual Children's } \\
\text { Performance in Ranking }\end{array}$ & $\begin{array}{l}\text { *From } \\
4^{\text {th }} \text { to 17th } \\
(\mathrm{N}=9)\end{array}$ & $\begin{array}{l}\text { **From }^{\text {st }} \text { to } 21 \mathrm{st} \\
(\mathrm{N}=15)\end{array}$ \\
\hline $\begin{array}{l}\text { Multilingual Children's } \\
\text { Performance (\% within } \\
\text { Group) }\end{array}$ & $\begin{array}{l}\text { Upper } \\
19.1 \%\end{array}$ & Upper 28\% \\
\hline
\end{tabular}

*Nine out of the 15 multilingual children performed within the top 17 in a class of 89 children. **Fifteen of the 22 multilingual children performed within the top 21 in a class of 75 children. The 4 highest performers in this group were multilingual children.

In the second grade, 9 of the 15 multilingual children ranked between $4^{\text {th }}$ and $17^{\text {th }}$ in performance among the entire group of 89 children, performing in the upper $19.1 \%$. In the third grade, 15 of the 22 multilingual children ranked between 1 st and $21^{\text {st }}$ in the entire group of 75 children, performing in the upper $28 \%$, while the highest 4 performers were multilingual children. Of the 164 children in School 2, 37 were multilingual, 24 of whose performance ranked within the top 21 children in the entire group.

Performance in School 3, where three groups (Grades 2, 3, and 4) were observed, results were mixed.. Grade 2 had 65 children, Grade 3 had 75 children, and Grade 4 had 90 children, a total of 230 children. Table 3 provides summary data on the performance of the multilingual children in the school, as was indicated by composite score rankings in the four selected subject areas, i.e., English, Kiswahili, Math and Science.

Table 3. Multilingual Children's Performance in School 3

\begin{tabular}{|l|l|l|l|}
\hline $\begin{array}{l}\text { Grade/ } \\
\text { Group }\end{array}$ & 2 & 3 & 4 \\
\hline Class Size & 65 & 75 & 90 \\
\hline $\begin{array}{l}\text { Number of Multilingual } \\
\text { Children }\end{array}$ & 14 & 15 & 23 \\
\hline $\begin{array}{l}\text { Multilingual Children's } \\
\text { Performance in Ranking }\end{array}$ & $\begin{array}{l}\text { *From } \\
\text { 3rd to } \\
64^{\text {th }} \\
\text { N=14 }\end{array}$ & $\begin{array}{l}\text { **From } \\
3 \text { rd to } \\
28^{\text {th }} \\
\mathrm{N}=11\end{array}$ & $\begin{array}{l}* * \text { From } \\
1 \text { st to } 31^{\text {st }}\end{array}$ \\
$\mathrm{N}=18$ \\
\hline $\begin{array}{l}\text { Multilingual Children's } \\
\text { Performance } \% \text { within } \\
\text { Group) }\end{array}$ & $\begin{array}{l}\text { Across } \\
\text { the } \\
\text { Range }\end{array}$ & $\begin{array}{l}\text { Upper } \\
37.3 \%\end{array}$ & $\begin{array}{l}\text { Upper } \\
34.4 \%\end{array}$ \\
\hline
\end{tabular}

*This group of multilingual children was spread across the entire range of the class performance.

**Eleven the 15 multilingual children studied performed within the upper 28 in a group of 75 children.

*** Eighteen of the 23 multilingual children performed within the upper 31 in a group of 90 children.

In school 3, children's performance was a wide range. In Grade 2, all 14 multilingual children performed across the spectrum, from $3^{\text {rd }}$ to $64^{\text {th }}$, which means that the multilingual children's performance did not stand out. In other words, some of the multilingual second graders were not doing well in the selected key school subjects. In Grade 3, 11 of the 15 children ranked between $3^{\text {rd }}$ and $28^{\text {th }}$, performing within the upper $37.3 \%$ of the total of 75 children. In the fourth Grade, 18 of the 23 multilingual children ranked within the upper 31 , performing within the top $34.4 \%$ of the group of 90 children. 


\subsection{Disadvantages of Using Only One of the Languages Children Spoke}

The follow-up interviews with teachers and parents revealed that children faced the following disadvantages when they were required to use only one of the languages they spoke: (i) children's learning potentials were lowered because they "could not function fully to connect learning within the family to learning in school", (ii) children's self esteem was lowered because their uniqueness and their creativity embedded in their languages were overlooked, (iii) Children's connection to their extended families were undermined because of seemingly no relevance to school learning, (iv) children might tend to focus narrowly on school requirements just to pass competitive exams but ignore knowledge and skills embedded in the other languages the children spoke. There were no disadvantages recorded in questionnaires or interviews with regard to children's use of multiple languages.

\subsection{Summary of Findings}

The study examined factors that contributed to and supported children's use of multiple languages; how fluency in multiple languages was related to thought processes, communication and school learning and performance in selected subjects. The study also revealed disadvantages of using only one of the languages children spoke. Parental use of multiple languages, interaction with extended family and peers were the main factors that contributed to, and supported, children's abilities to use multiple languages. The different sets of data converged to show positive learning outcomes for young children using multiple languages in their everyday functioning at home and in school. Multilingual children did not feel constrained to use only one language in their classrooms. Their teachers allowed some flexibility even though the language policy emphasized Kiswahili and English. Children expressed their thoughts and asked questions clearly in class using different languages. This was seen as an effective way to communicate and to learn. Performance of multilingual children among their monolingual peers was ranked considerably high.

\subsection{Composite Score Rankings on Performance}

School performance of a total of 107 multilingual children $(16 \%)$ were observed within a larger group of 668 children in 10 classrooms in 3 schools. Composite score ranks were studied as secondary data in 10 classrooms in 3 schools. It was evident from the data that most multilingual children studied were doing well in the school subjects designated as key curriculum subjects, i.e., English, Kiswahili, Math and Science. These subjects were considered the most important by both teachers and parents in all 3 schools. In School 1, all but one of the 18 multilingual children performed better than $71 \%$ of their respective class groups. The highest 4 performers in School 2 were multilingual children. In this school, 24 of the 37 multilingual children ranked within the top 21 of the entire group of 164 children, i.e. they performed within the top $12.8 \%$ of the group. Results from School 3 were different. Second graders were not performing well in the selected subjects. In the second grade with 65 children, the 14 multilingual children ranked anywhere between $3^{\text {rd }}$ and $64^{\text {th }}$. The other 29 out of 38 multilingual children in School 3 ranked within the top 31, performing in the top $19 \%$ of the group of $1653^{\text {rd }}$ and $4^{\text {th }}$ graders.

Of the 107 multilingual children, $70 \quad(65.4 \%)$ performed within the top $34 \%$ of their respective groups, or better. Other than the 14 children in the second grade in School 3, none of the multilingual children studied seemed to do poorly on the key curriculum subjects. Of the remaining 37 (107-70) multilingual children, 23 (about $21.5 \%$ of the group of 107) performed within the upper half of their respective groups; while the remaining 14 (13.1\% of the 107) ranked from top to bottom in their class (the second graders in School 3). Even though the study did not seek to establish gender differences in performance, the secondary data identified male and female students, but the analysis did not show any gender differences.

\subsection{Synthesis of Findings}

The data from parents' questionnaires, and interviews, and the secondary data analyzed on children performance point in one direction, which is. support of children's multiple languages and generally high performance in school The following statements are drawn from the data presented and analyzed:

- Children learned multiple languages informally within their home and community environments.

- Several factors contributed to effectiveness of learning multiple languages in the young children, including parental use of the multiple languages, interaction with extended family and intergenerational interaction.

- Teacher interview responses showed that multilingual children used all their languages formally and informally, both outside class and during class sessions. Code switching was done regularly during class sessions. 
- Teacher interviews also indicated that when children used all languages interchangeably within class sessions, communication was clearer than when using only Kiswahili, the national language. However, classroom observations revealed that multilingual children expressed themselves most clearly when they used Kiswahili. English was the most difficult language for children to use in expressing themselves.

- Even though the Tanzanian language policy is to use English and Kiswahili as languages of instruction, teachers were more flexible in the classroom, and allowed children to use their other languages as was necessary. It happened that the teachers also spoke the same languages. It seemed that the language policy was more on official, written documents than in the classroom interactions with children.

- Most multilingual children observed (65.4\%) performed within the top $34 \%$ or higher; within their respective groups; $21.5 \%$ performed within the upper half of their respective groups, and the remaining $13.1 \%$ performed across the spectrum, i.e., anywhere from highest to lowest within the group. This means that, $86.9 \%(65.4 \%+21.5 \%)$ of the multilingual children observed performed at the 50th Percentile or better within their respective groups.

\section{Conclusion}

The findings of this study highlight the importance of children's holistic learning. Children need all learning tools they have access to, both at home and at school, with the most important tool being the languages they speak. Use of multiple languages was perceived as a non-issue at the least and a positive catalyst at the most, by parents and teachers as well. Parents and the extended family play an important role in a child's holistic learning. The pre-determined school curriculum can include teacher flexibility that is supported by parents to help multilingual children learn to their highest potential. Research has demonstrated that submersion is not an effective way to support young children with multiple languages [20]. Priority has to be on making connections between the languages that embody children's early foundation for learning and the subsequent exposure to planned school curriculum. When children learn concepts from multiple perspectives using the languages they speak, their understanding is broadened to create room for inquisitiveness and creativity. The young children's fluency in multiple languages and the use of those languages in school learning were found to be useful assets. This may help to further curb the social inequity in the Tanzanian early education [21] and in other linguistically similar contexts.

\section{Implications for Further Research}

This study involved 107 multilingual children in 10 classrooms within 3 schools in the Tanzanian context. These findings cannot be applied directly to contexts in which children are not fully multilingual. The definition of bilingual or multilingual children as children "who speak one language (L1) and are in the process of learning English and/or another language (L2)", does not apply to the findings of this study. The children studied in this research acquired at least two languages naturally from birth, were fluent in all languages, and were learning English at the time of the study. Contextualized, more comprehensive research involving larger numbers of bilingual/multilingual children is necessary. Such research must include the role of language policy. As comprehensive, contextualized studies grow in number, it will be possible to develop a research-based theory of the role of fluency in multiple languages in young children's school learning. Classroom practice can begin to catch up faster with neuroscience, with regard to natural mastery of multiple languages in early childhood and embrace the possible learning advantages.

\section{References}

[1] Eliot, L. and Syc, S. "Language and the Brain". In Linda, Gilkerson and Rebecca Klein, (eds.). Early Development and the Brain: Teaching Resources for Educators. Erikson faculty Development Project on the Brain, Washington D.C. Zero-toThree, 2008.

[2] Piper, T., Language and Learning: the Home and the School Years, 2nd edition, New Jersey: Merrill, 1998.

[3] Owens, R. E. Jr., Language Development: An Introduction, Seven Edition, Toronto: Pearson, 2008.

[4] McLean L., and Snyder-McLean, L., A Transactional Approach to Early Language Training. Columbus, Ohio: Merrill,1978.

[5] Bowerman, M., Discussion of Summary: "Development of Concepts Underlying language", In R. Schiefelbusch and L. Lloyd (Eds.), Language Perspectives: Acquisition, retardation and Intervention, Baltimore, park Press, 1974.

[6] Kuhl, P., The Linguistic Genius of Babies. PBS Video (Clip 10 minutes and 15 seconds long with over 1.6 million views by Nov. 2014). http://www.ted.com/_talks/patricia_ kuhl_the_linguistic_genius_of_babies/, 2010. (Access Date: March 5, 2016). 
[7] Paradis, J., Grammatical Morphology in Children Learning English as a Second Language: Implications of Similarities with Specific Language Impairment. Language Speech Hear Serv. Sch.2005; 36:172-87.

[8] Hernàndez A.E., Bates E, Avila LX., "Sentence Interpretation in Spanish-English bilinguals: What does it mean to be in-between?" Applied Psycholinguistics, 1994, $15: 417-66$

[9] Karlson, L. C., Soveri, A., Rasanen, P., Karna, A., delate, S., Lagerstrom, E., Mard, L., Steffansson, M., Lehtonen, M. and Laine, M., "Bilingualism and Performance on Two Widely Used Developmental Neuropsychological Test Batteries", Open Access, Peer Reviewed Research Report, 15, 2015, 10.1371/journal.pone.01258567.

[10] Armstrong, P. W. and Rogers, J. D., "Basic Skills Revisited: The Effects of Foreign Language Instruction on Reading Math and Language Arts". Learning Languages, 2(3), 1997, 20-31.

[11] Mushi, S. L. P. A Global Analysis of Education in the 21st Century: What Kinds of Schools Do We Need Today? Lewiston-Lampeter: The Edwin Mellen Press, 2015.

[12] Berk, L., Infants and Children: Pre-Natal Through Middle Childhood, 7th edition, New York: Pearson, 2014.

[13] Eliot, L., What's Going on in There? How the Brain and Mind Develop in the First Five Years of Life. New York: Bantam Books, 1999.

[14] Petito, L. A., Katerelos, M., Levy, B., Guana, K., Tetreault, K. and Ferraro, V., "Bilingual Sign and Spoken Language Acquisition From Birth: Implications for Mechanics Underlying Early Bilingual Language" Acquisition. Journal of Child Language 28, 2001, 453-486.

[15] Buschmann, A., and Sachse, S., (2018). Heidelberg Interaction Training for Language Promotion in Early Childhood Settings, European Journal of Education, (2018). v53 n1 pp66-78 13pp1

[16] Curdt-Christiansen, X. L.; Wang, W. Parents as Agents of Multilingual Education: Family Language Planning in China. Language, Culture and Curriculum, v31 n3 p235-254 2018. $20 \mathrm{pp}$

[17] Blair, A., and Haneda, M.. Toward Collaborative Partnerships: Lessons from Parents and Teachers of Emergent Bi/Multilingual Students, Theory into Practice, (2021), (v60 n1 p18-27 2021. 10 pp

[18] Festman, J. Learning and Processing Multiple Languages: The More the Easier? Language Learning, (2021), v71 suppl 1 p121-162 Mar 2021. (EJ1286692)

[19] Ferjan, R. N. and Kuhl, P. Bilingual Baby: Foreign Language Intervention in Madrid's Infant Education Centers, Mind, Brain, and Education, (2017). v11 n3 p133-143 11pp
[20] Jorden's K., Van den Branden K., and Van Gorp K.., Multilingual Islands in a Monolingual Sea: Language Choice Patterns During Group Work., International Journal of Bilingual Education and Bilingualism, (2018). v21 n8 p943$95513 p p$

[21] Baum, D. R., and Hernandez, J. E., Early Childhood Education for All: A Mixed-Method Study of the Global Policy Agenda in Tanzania, Early Years: An International Journal of Research and Development, (2019). v39 n3 p260275 2019. 16 pp. 